\title{
Structural Response of Piping to Internal Gas Detonation
}

\author{
Joseph E. Shepherd \\ Graduate Aeronautical Laboratories, \\ California Institute of Technology, \\ Pasadena, CA 91125 \\ e-mail: jeshep@caltech.edu
}

Detonation waves in gas-filled piping or tubing pose special challenges in analysis and prediction of structural response. The challenges arise due to the nature of the detonation process and the role of fluid-structure interaction in determining the propagation and arrest of fractures. Over the past 10 years, our laboratory has been engaged in studying this problem and developing methodologies for estimating structural response. A brief overview of detonation waves and some key issues relevant to structural waves is presented first. This is followed by a summary of our work on the elastic response of tubes and pipes to ideal detonation loading, highlighting the importance of detonation wave speed in determining flexural wave excitation and possibility of resonant response leading to large deformations. Some issues in measurement technique and validation testing are then presented. The importance of wave reflection from bends, valves, and dead ends is discussed, as well as the differences between detonation, shock wave, and uniform internal pressure loading. Following this, we summarize our experimental findings on the fracture threshold of thin-walled tubes with pre-existing flaws. A particularly important issue for hazard analysis is the estimation of loads associated with flame acceleration and deflagration-to-detonation transition. We give some recent results on pressure and elastic strain measurements in the transition regime for a thick-wall piping, and some remarks about plastic deformation. [DOI: 10.1115/1.3089497]

\section{Introduction}

The goal of this paper is to summarize the state of knowledge about gaseous detonation loading of piping and indicate some of the more important issues that have to be considered in analyzing these problems. Detonation of gaseous mixtures inside of piping systems is of interest to the practicing engineer and as a subject of scientific investigation [1,2]. It is a hazard that is occasionally encountered in the chemical $[3,4]$, nuclear [5-8], and transportation industries [4]. In some technologies like pulse detonation engines [9], detonations are deliberately created. The coupling between detonations and structures like pipes is a model for fluidstructure interaction, which has been extensively examined in the closely related subject of shock (blast wave) or impact loading of structures $[10,11]$.

The response of pipes to detonations is part of the broader problem of designing or analyzing the ability of pressure vessels to contain internal gaseous explosions. Broadly speaking, gas explosions can be characterized into two categories: low-speed flames or deflagrations and high-speed coupled shock and reaction waves known as detonations [12]. Deflagrations are subsonic, usually turbulent, flames that cause slow pressurization that is treated as a quasistatic, spatially nonuniform structural load. Detonations are supersonic waves that result in dynamic structural loading that is spatially nonuniform. The peak pressures in detonations are usually about twice as high as for a deflagration and, in exceptional cases, may be as much as ten times higher.

There is some guidance on structural design for deflagrations contained in NFPA 69 [13], which refers to the ASME Boiler and Pressure Vessel Code Section VIII, Division 1, Part H. It is quite clear that detonations are excluded from these considerations since the pressure loading of a deflagration is restricted to the quasistatic regime. At present, there is no provision within the

Contributed by the Pressure Vessel and Piping Division of ASME for publication in the Journal of Pressure Vessel Technology. Manuscript received April 28, 2007; final manuscript received December 26, 2008; published online April 13, 2009. Review conducted by Boris Blyukher. Paper presented at the 2006 ASME Pressure Vessels and Piping Conference (PVP2006), Vancouver, BC, Canada, July 23-27, 2006
ASME Boiler and Pressure Vessel or Piping Codes for designing pressure vessels or piping to withstand gaseous detonations.

Recently, an ASME Code Case [14] has been developed for designing high-explosive containment vessels based on extensive work by Los Alamos [15,16] to formulate ductile failure criteria. Although focused on high explosives, the material response aspect of the Los Alamos work is quite relevant to the present study. A key idea is the reliance on modern fracture mechanics [17] to design vessels that will plastically deform but not catastrophically fail under extreme impulsive loading. Many of these ideas are directly applicable to the situation of gaseous detonation but there are some crucial distinctions. High explosives are usually approximated as impulsive loads, and the standoff between the vessel and the explosive is a significant aspect of the loading magnitude. Gaseous explosions usually result in a combination of step and impulse loading, and the gas is often assumed to completely fill the vessel or pipe. Deliberate high-explosive detonations inside containment vessels are controlled events while gaseous detonations often are the result of an uncontrolled ignition process that can result in very high localized pressures if the deflagration accelerates to detonation (deflagration-to-detonation transition (DDT) [18]). In addition, the propagation of the explosion wave in the gas adjacent to the vessel or tube may result in a strong coupling between the pressure wave and the structural response.

\section{Detonation Waves}

A detonation wave $[2,19]$ consists of a shock wave closely followed by a chemical reaction zone in which the fuel and oxidizer rapidly react to produce hot (temperatures of 2000-3000 K) combustion products. An ideal detonation travels at a nearly constant speed close to (usually within 90\%) the theoretical or ChapmanJouguet $(\mathrm{CJ})$ velocity $U_{\mathrm{CJ}}$, which is between $1500 \mathrm{~m} / \mathrm{s}$ and 3000 in gases depending on the fuel-oxidizer combination, see Table 1. The reaction zone in a detonation is usually very thin, less than 10 $\mathrm{mm}$ for most stoichiometric fuel-air mixtures and less than $100 \mu \mathrm{m}$ for stoichiometric fuel-oxygen mixtures. Due to reaction zone instability, the effective width of the reaction zone (characterized by the detonation cell width $S$ ) is typically $10-100$ times larger than the idealized reaction zone [20-22]. Within this reaction zone, temperature, pressure, and other properties change rap- 
Table 1 Measured and computed detonation parameters for stoichiometric mixtures at standard initial conditions $\left(25^{\circ} \mathrm{C}, 1 \mathrm{~atm}\right)$

\begin{tabular}{|c|c|c|c|c|c|}
\hline Fuel & & $\begin{array}{c}\text { Volume } \\
(\%)\end{array}$ & $\begin{array}{c}U_{\mathrm{CJ}} \\
(\mathrm{m} / \mathrm{s})\end{array}$ & $\begin{array}{c}P_{\mathrm{CJ}} \\
(\mathrm{bar})\end{array}$ & $\begin{array}{c}S \\
(\mathrm{~mm})\end{array}$ \\
\hline \multicolumn{6}{|c|}{ Fuel-air mixtures } \\
\hline Hydrogen & $\mathrm{H}_{2}$ & 29.6 & 1971 & 15.6 & $6-10$ \\
\hline Acetylene & $\mathrm{C}_{2} \mathrm{H}_{2}$ & 7.75 & 1867 & 19.1 & $10-15$ \\
\hline Ethylene & $\mathrm{C}_{2} \mathrm{H}_{4}$ & 6.54 & 1825 & 18.4 & $24-26$ \\
\hline Ethane & $\mathrm{C}_{2} \mathrm{H}_{6}$ & 5.66 & 1825 & 18.0 & $50-59$ \\
\hline Propane & $\mathrm{C}_{3} \mathrm{H}_{8}$ & 4.03 & 1801 & 18.3 & $40-60$ \\
\hline Methane & $\mathrm{CH}_{4}$ & 9.48 & 1804 & 17.2 & $250-350$ \\
\hline \multicolumn{6}{|c|}{ Fuel-oxygen mixtures } \\
\hline Hydrogen & $\mathrm{H}_{2}$ & 66.7 & 2841 & 19.0 & $1-2$ \\
\hline Acetylene & $\mathrm{C}_{2} \mathrm{H}_{2}$ & 28.6 & 2425 & 34.0 & $0.1-0.2$ \\
\hline Ethylene & $\mathrm{C}_{2} \mathrm{H}_{4}$ & 25.0 & 2376 & 33.7 & $2-3$ \\
\hline Ethane & $\mathrm{C}_{2} \mathrm{H}_{6}$ & 22.2 & 2372 & 34.3 & $1-2$ \\
\hline Propane & $\mathrm{C}_{3} \mathrm{H}_{8}$ & 16.7 & 2360 & 36.5 & $0.5-1$ \\
\hline Methane & $\mathrm{CH}_{4}$ & 33.3 & 2393 & 29.6 & $2-4$ \\
\hline
\end{tabular}

idly while just downstream of the reaction zone, a much slower variation occurs due to the gas dynamics of the wave propagation process. The pressure just behind the detonation can be as high as 20-30 times the ambient pressure, depending on the fuel-oxidizer mixture, see Table 1. The computations were carried out with standard thermochemical equilibrium methods [23-25].

The values in Table 1 are only representative of detonation parameters; all values will depend strongly on composition, and the results in the table are for stoichiometric mixtures only. Detonation velocities, pressures, and cell widths will all depend on the ratio of fuel to oxygen and the amount and type of additional gas components such as nitrogen. Detonation properties will also depend on initial pressure and temperature. To evaluate the hazard for a specific mixture and initial conditions, computations or measurements for that particular situation should be carried out.

A typical experimental pressure-time trace for a detonation propagating longitudinally from the closed end of a tube is shown in Fig. 1. The almost instantaneous jump in pressure at time $t=0$ corresponds to the passage of the detonation wave across the measuring station. The rapid decrease in pressure in the first $0.01 \mathrm{~ms}$ is associated with the reaction zone. The more gradual decrease in pressure out to $t=0.25 \mathrm{~ms}$ and plateau for longer times is associated with the gas dynamics of the flow behind the wave. Superimposed on the general trend are pressure fluctuations due to the unstable nature of the coupling between chemical kinetics and the leading shock front [19]. This instability consists of weaker shock waves propagating transversely to the main front and organized in a quasiperiodic structure that creates a cellular structure on sooted foils placed with the detonation tube [27], see Fig. 2.

The spacing $S$ of the transverse waves (detonation cell width) observed on sooted foils (see Table 1) has been measured [31] for

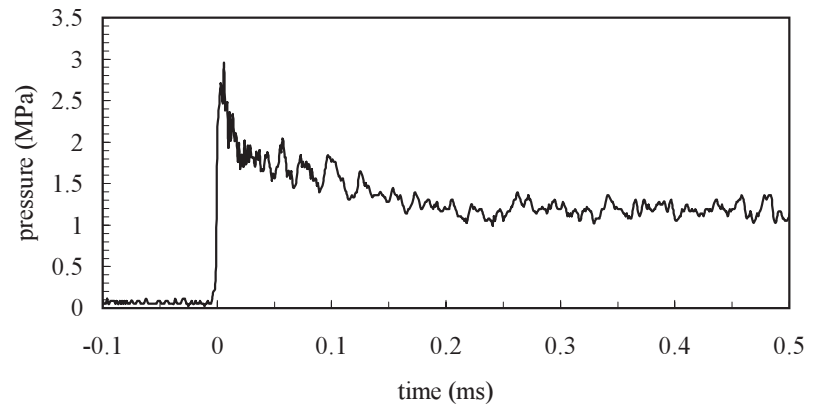

Fig. 1 Measured pressure versus time for detonation loading [35] many mixtures and can be used as a measure of the sensitivity of a mixture to detonation. The smaller the cell size, the easier it is to initiate and propagate detonations. As shown in Table 1, mixtures of fuel and oxygen have cells that are much smaller than fuel and air, in agreement with the observed ease of detonation [32].

The fluctuating pressure is usually ignored in structural models, and only the average pressure is considered computing the force (loading) on the tube wall. In terms of a structural load, the net effect of a detonation is to produce a spatially nonuniform propagating load, as shown in Fig. 3. Experimental pressure traces and gas dynamic models can be used to define an idealized loading profile. For a tube with a closed end, the situation can be characterized by three regions (see Fig. 3). First, there is the initial mixture ahead of the detonation front. Since the detonation wave propagates supersonically, there is no loading produced ahead of the detonation front and the pressure at a fixed location jumps up suddenly when the detonation front arrives there. The detonation front consists of the shock wave and reaction zone, which is not resolved in the loading model. The peak pressure just behind the front $P_{2}$ can be approximated by the CJ value, computed with the same thermochemical equilibrium codes that are used to obtain the detonation velocities. The detonation is followed by an expansion wave that extends to approximately midway between the wave front and the initiation end of the tube. Behind the expansion wave the gas is stationary and the pressure $P_{3}$ in this region is approximately $0.4 P_{\mathrm{CJ}}$.

The ideal pressure distribution in such a tube can be described with an analytical solution known as the Taylor-Zeldovich model $[33,34]$. The expansion wave region stretches as the wave propagates and the profile evolves in a self-similar fashion with the similarity parameter $\left.x / U_{\mathrm{CJ}} t\right)$ and the leading pressure wave propagating at the Chapman-Jouguet detonation velocity $U_{\mathrm{CJ}}$. This ideal solution is commonly used as a base for modeling the pressure distribution required from structural loading computations; a simple approximation in terms of an exponentially decaying solution can also be used, as discussed in Appendix B of Beltman and Shepherd [35].

For long tubes and high temperature mixtures, significant heat transfer and frictional effects will modify the pressure profile [36]. As thermal energy is transferred into the tube, the temperature and pressure of the gas will drop more rapidly than due to the isentropic expansion of the ideal Taylor-Zeldovich model and the tube will heat up. Edwards et al. [37] found that after the detonation had propagated about 70 tube diameters, the pressure profile actually became steady relative to the detonation front itself; in other words, the expansion wave reaches a fixed extent once the wave has propagated sufficiently far. A second consequence is that the 


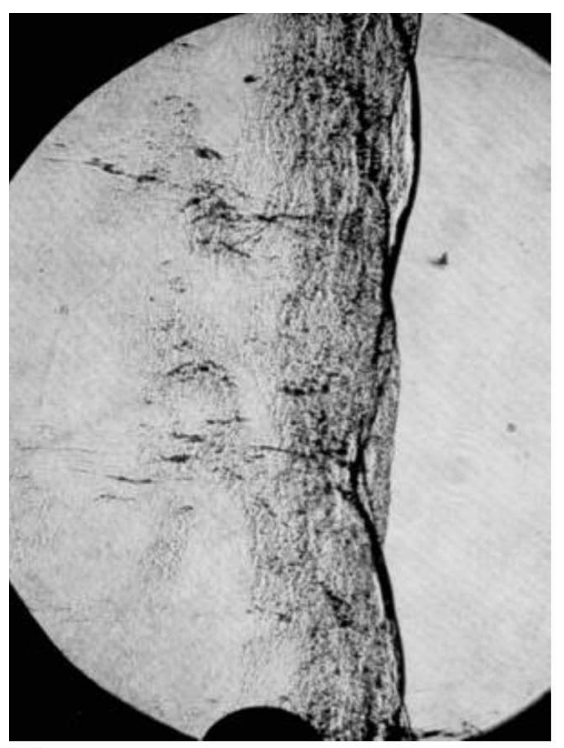

(a)

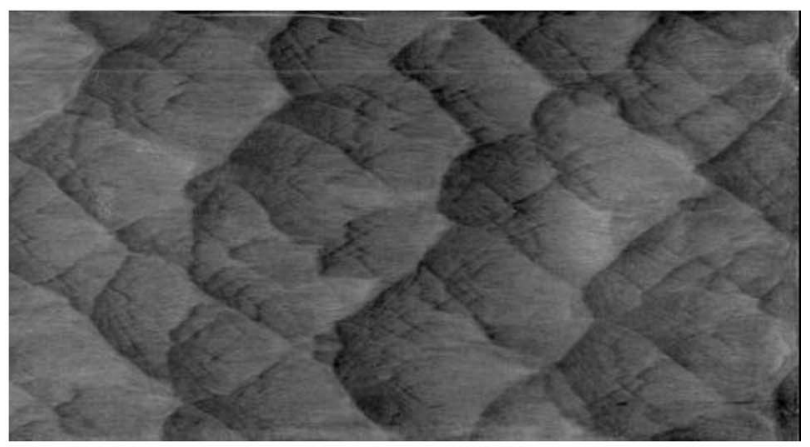

(b)

Fig. 2 (a) Shadow image of a detonation front in $2 \mathrm{H}_{2}-\mathrm{O}_{2}+3 \mathrm{~N}_{2}$ at $20 \mathrm{kPa}$; propagation is left to right. The instability of the front is manifested by the curved and kinked leading shock; the fine-scale density fluctuations behind the front and the secondary shock waves extending into the products at the left of the wave. (b) Cellular pattern on sooted foil created by a detonation in $2 \mathrm{H}_{2}-\mathrm{O}_{2}+2 \mathrm{~N}_{2}$ at $20 \mathrm{kPa}$. The cell size for this mixture is approximately $43 \mathrm{~mm}$ and the soot foil is about $150 \mathrm{~mm}$ wide [28-30].

thermal energy that is deposited into the tube will set up thermal stresses [38], increasing the strain within the tube in addition to the mechanical strain induced by the internal pressure load. In general, for detonations the thermal stresses are much lower than the peak stresses that occur due to the mechanical load. Since the heat transfer into the pipe is relatively slow, the peak thermal stresses occur at long times compared with the detonation loading duration. As a consequence, thermal stress is a much more significant issue for deflagration-type explosions than detonations and may result in strains much larger than the mechanical strain alone.

In addition to the main pressure loading shown in Fig. 3, idealized models [39] predict the existence of a pressure peak (Von Neumann spike) at the front of the reaction zone with a value approximately double that of the Chapman-Jouguet pressure. This pressure spike is usually not resolved in experiments because of its localized nature and short duration. Since the reaction zone is of such a short length compared with a typical tube length, the influence on the structural response is small in comparison with the effects of the main loading produced by the Taylor-Zeldovich pressure profile behind the detonation front. For these reasons, the influence of the Von Neumann pressure spike on the structural response is usually neglected.

\section{Elastic Response}

From a structural point of view, the tube experiences a traveling internal load that produces transient deformation of the tube. This situation is similar to the case of a gaseous shock wave propagating in a tube [26] but with a slightly more complex temporal (Fig. 1) and spatial (Fig. 2) variation in internal pressure than the simple step function that can be used to represent a shock wave. For an ideal wave, the pressure initially jumps to the CJ value $P_{\mathrm{CJ}}$ and then decays to the plateau value $P_{3}$ after the Taylor wave has passed and the fluid has come to rest. If the CJ pressure is sufficiently small (defined subsequently), then the motions of the tube wall will be elastic and no permanent deformation will occur when the detonation passes through the tube. On the other hand, for sufficiently large values of the CJ pressure the yield strength of the tube will be exceeded and plastic deformation will ensue. In this section we will review the elastic case and we will consider the problem of plastic response in Sec. 5 .

Extensive results [35] in the form of measurements, analytical theories based on shell models, and numerical simulations are available for the case of elastic motion created by propagating detonations or shock waves. The key results are that the wave acts

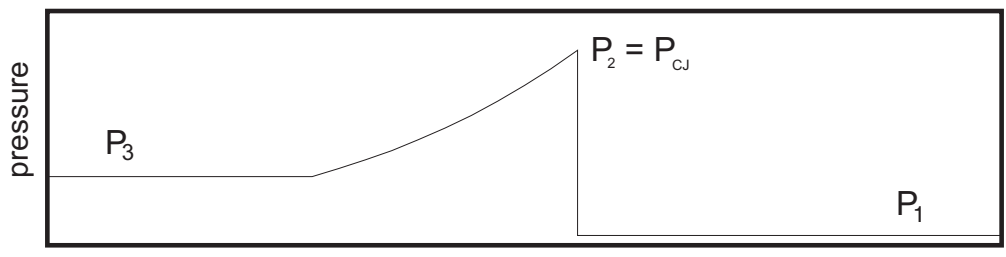

distance

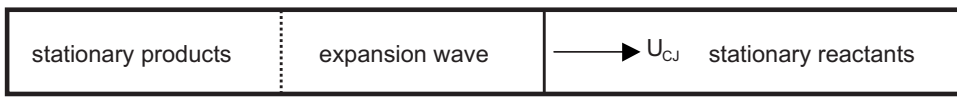

detonation

Fig. 3 Detonation propagation in tube with closed ends: initiation at the left-hand side and propagation from left to right [35] 
as a traveling load, which produces progressive flexural waves having a phase speed equal to the load speed. The mode and peak amplitudes of the deformations depend on the speed of the wave as compared with the characteristic group velocities of the various elastic modes of tube oscillations.

3.1 Modeling. The simplest approach [40], often used in hazard analyses for quick estimates of peak deflection, ignores the axial distribution of pressure (or equivalently, the bending resistance of the tube) and assumes that the transient pressure load at a location (Fig. 1) can be used as the forcing function for a singledegree-of-freedom (radial motion only) of the tube structure. The axisymmetric radial vibrations [41] of a long (axially unconfined) cylinder have a fundamental frequency of

$$
f=\frac{1}{2 \pi R} \sqrt{\frac{E}{\rho\left(1-\nu^{2}\right)}}
$$

corresponding to an oscillation period of

$$
T=1 / f
$$

The time required for elastic wave transit time through the thickness $h$ is

$$
\tau_{\text {wave }}=h / c_{l}
$$

where the longitudinal sound speed $c_{l}$ is typically between 5500 $\mathrm{m} / \mathrm{s}$ and $6000 \mathrm{~m} / \mathrm{s}$ for metals so that

$$
\tau_{\text {wave }} \ll T
$$

Therefore, even under gaseous detonation loading it is not necessary to consider [42] elastic wave motion through the thickness but only the structural modes that involve the bulk radial motion of the pipe wall. The single-degree-of-freedom model describes the radial deflections as simple forced harmonic motions

$$
\frac{\partial^{2} x}{\partial t^{2}}+\omega^{2} x=\frac{\Delta P(t)}{\rho h}
$$

where the oscillator natural frequency $(\mathrm{rad} / \mathrm{s})$ is

$$
\omega=2 \pi f
$$

and $f$ is given by Eq. (1). Solutions of this model for elastic systems and extensions to the elastoplastic case are discussed in great detail by Biggs [43] as well as by Baker et al. [11] for a variety of forcing functions $\Delta P(t)$. The key result for shock and detonation loading is that the peak deformation is primarily a function of the characteristic duration of the pressure pulse $\tau$ as compared with the structural period $T$. For pulses significantly shorter than the period $\tau<T / 4$, the loading is in the impulsive regime and the peak deformation will scale linearly with the impulse, defined as the time integral of the pressure. For long duration pulses, $\tau>T$, the loading is in the step function regime and the peak deformation will be independent of the pressure history and equal to twice the static deflection that would be obtained for the steady pressure equal to the peak value. For intermediate values of $\tau / T$, the peak deformation will depend on the details of the time history and can be described in terms of a theoretical dynamic load factor $\Phi(\tau / T)$, as defined in Eq. (11).

In order to go beyond this simple approach, it is necessary to consider the axial distribution of loading and the deformation, taking into account the bending stiffness of the tube that results in coupling the radial and axial motion. The first comprehensive theories for predicting the elastic response of a tube to a moving load were developed by Tang [44] and Reisman [45], who used transient shell theory to model the structural response. By assuming a tube of infinite length, the problem reduces to a "steadystate" problem and an analytical solution for the shell motion can be obtained. The model presented by Tang includes the effects of rotatory inertia and transverse shear. He also presented transient results for a finite length shell using the method of characteristics. Reismann [45] developed a model that includes the effect of pre-
Table 2 Examples of tubes and computed parameters including critical and characteristic speeds

\begin{tabular}{lccc}
\hline \hline Material & Al 6061 & SS 304 & AISI 1010 \\
\hline Thickness $(\mathrm{mm})$ & 1.5 & 25.4 & 1.5 \\
Radius $(\mathrm{mm})$ & 19.9 & 152 & 64.5 \\
$f_{\text {hoop }}(\mathrm{kHz})$ & 42 & 5.4 & 13.4 \\
$X_{\lambda}(\mathrm{mm})$ & 4.3 & 48 & 7.6 \\
& & & \\
& Speed $(\mathrm{m} / \mathrm{s})$ & & \\
$V_{c 0}$ & 1013 & 1455 & 614 \\
$V_{c 1}$ & 2847 & 2797 & 2922 \\
$c_{s}$ & 3055 & 3070 & 3208 \\
$V_{c 2}$ & 4982 & 4912 & 5172 \\
$V_{c 3}$ & 5278 & 5116 & 5422 \\
$c_{l}$ & 6064 & 5554 & 6001 \\
\hline \hline
\end{tabular}

stress on the structural response and gave an elegant explanation of how the resonant coupling between a moving load and the flexural waves comes about. Simkins [46-48] extended the analysis to thick-wall tubes and first applied these ideas to explain observations of large strain amplitudes in gun tubes.

The Tang model was applied to the case of ideal detonation loading by Beltman [35], and analytical solutions for the deformations were given for the case of a steady-state wave. One of the key results is the prediction of peak structural deflections as a function of wave speed and the possibility of resonant response at four critical speeds. These speeds are found as a solution to the characteristic equation describing the dispersion relationship [44]. The most relevant speed for detonation problems is lowest critical speed $V_{c 0}$, which corresponds to the group velocity of flexural waves that consist of coupled radial-bending oscillations. A simpler model was given by Simkins [46], whose analysis neglects rotatory inertia and shear deformation. In this model, there is a closed form for the first critical speed $V_{c 0}$, which is useful for estimation

$$
V_{c 0}=\left[\frac{E^{2} h^{2}}{3 \rho^{2} R^{2}\left(1-\nu^{2}\right)}\right]^{1 / 4}
$$

Solutions of the dispersion relation typically give values that are up to $10 \%$ lower than Eq. (7).

The other critical velocities are $v_{c 1}$, equal to the modified shear wave speed

$$
V_{c 1}=\sqrt{\frac{\kappa G}{\rho}}
$$

the dilatational wave speed in a bar,

$$
V_{c 2}=\sqrt{\frac{E}{\rho}}
$$

and $V_{c 3}$, equal to the dilatational wave speed

$$
V_{c 3}=v_{d}=\sqrt{\frac{E}{\rho\left(1-\nu^{2}\right)}}
$$

where $E$ is Young's modulus, $G$ is the shear modulus, $\nu$ is Poisson's ratio, $\rho$ is the density, and $\kappa$ is the shear correction factor. For a more detailed discussion on the formulation and solution of the dispersion relation, see Ref. [44] or Ref. [35]. Two other relevant velocities are the bulk shear wave speed $c_{s}$ and longitudinal dilatational wave speed $c_{s}$. Examples of characteristic speeds for two different types of tubing are given in Table 2.

Comparing these speeds with the detonation velocities in Table 1 , it appears that most stoichiometric mixtures have CJ velocities between $V_{c 0}$ and $V_{c 1}$. For sufficiently low detonation speeds (lean or diluted mixtures), the CJ speed could be comparable to $V_{c 0}$; for 
mixtures diluted with sufficient amounts of helium or hydrogen, the detonation velocity may be comparable to $V_{c 1}$. In either case, the possibility of resonant excitation of the tube motion exists.

The existence of critical velocities and the potential for resonance effects were first recognized in the investigation of the response of railroad tracks and bridges to the passage of a train or other heavy load. That physical situation can be modeled as a beam on an elastic foundation with a moving load, which results in a governing equation that is identical to the simplest thincylinder model of a shock or detonation wave in a tube. The solution for the radial tube motion becomes unbounded when the loading travels at the critical speed of this model. Although a resonant response is observed in the experiments, various nonideal effects such as damping, nonlinearities, and ultimately plastic deformation limit the peak amplitudes to finite values.

In actual practice, detonation tubes have a finite length and transient effects may be important, particularly in the near resonant cases. Beltman [35] carried out analytical transient solutions by dropping the effects of rotary inertia and transverse shear from the Tang model. More general cases were treated by Beltman [35] using the finite element method. The analytical transient model was extended by Mirzaei et al. [49] to include the effects of rotary inertia and transverse shear, yielding improved agreement of the modeled hoop strains with the experiments [35].

3.2 Experiments. The earliest experiments on detonationinduced vibrations were carried out by de Malherbe et al. [40], who compared the results of the single-degree-of-freedom model to experimental values of hoop strain produced by propagating $\mathrm{H}_{2}-\mathrm{O}_{2}$ detonations in a $2 \mathrm{ft}(0.61 \mathrm{~m})$ diameter, $20 \mathrm{ft}(6.1 \mathrm{~m})$ long stainless steel tube. They found reasonable agreement between the measured and computed maximum strains and the frequency of oscillation. Transverse and longitudinal strains in polyvinylchloride (PVC) and stainless steel pipes with diameters between 16 $\mathrm{mm}$ and $33 \mathrm{~mm}$ were measured by Brossard and Renard [50] using detonations in $\mathrm{C}_{3} \mathrm{H}_{8}-\mathrm{O}_{2}-\mathrm{N}_{2}$ mixtures. The results for the PVC tubes were found to be quite different than for stainless steel, which was attributed in part to the visco-elastic properties of PVC. Van de Ven et al. [51] analyzed the response of a tube to an internal dust detonation with a nonrotatory symmetric pressure loading. They presented dynamic amplification factors derived from experimentally determined strains. Sperber et al. [52] measured strains produced in a thick-wall tube by an acetylene decomposition detonation. They noted that the peak strains were underpredicted by a factor of up to 4 when static formulas were used to estimate the maximum deformation. Thomas [53] carried out experiments in two types of plastic (glass-reinforced plastic (GRP) and medium density polyethylene (MDPE)) pipes using ethylene-air mixtures and detonation initiation by a spark-ignited oxy-acetylene booster. A longitudinal strain signal was observed propagating slightly ahead of the detonation wave and the strain signals appeared to be significantly different than those observed in shock wave experiments [26] with metal tubes.

Experiments on gun tubes $[46,47]$ revealed that the propagation speed of the load is an important parameter. Peak strain amplitudes up to three times higher than those predicted by the static Lamé formula were observed when the propagation speed of the load approached a critical value. Further investigation [46,48,54] showed that the radial motion created by the traveling load was being resonantly coupled into flexural waves when the load propagation velocity approached the flexural wave group speed. More recently, Beltman et al. [26] observed the same effect in an experimental and analytical investigation into the structural response of a thin shell to internal shock loading. Subsequently, Beltman and Shepherd [35] investigated the case of detonation loading and showed that resonance effects can be observed experimentally. Not only do the resonance effects amplify the peak strains, they can also produce uncompensated accelerations in piezoelectric

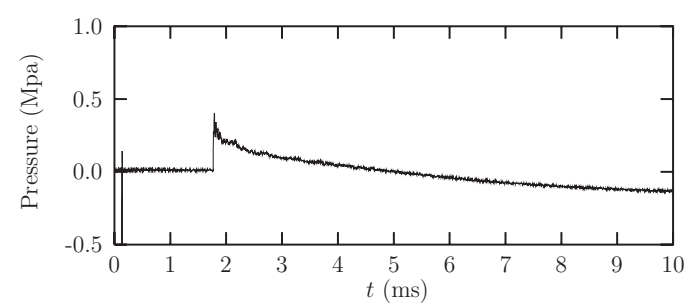

(a)

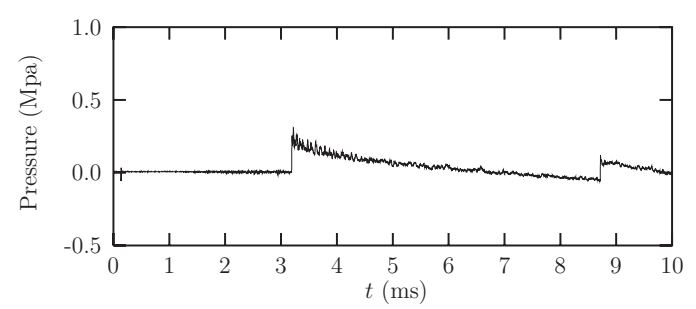

(b)

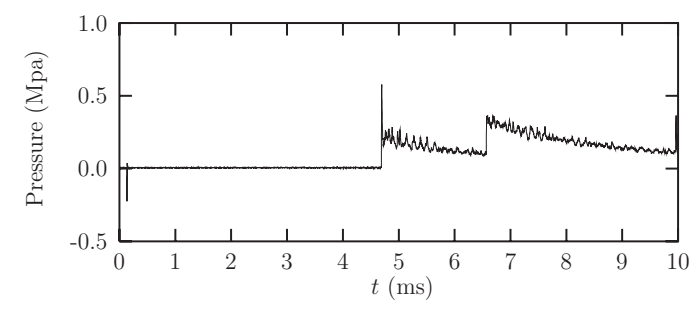

(c)

Fig. 4 Measured pressure signals for a detonation propagating at $1267 \mathrm{~m} / \mathrm{s}$ in the GALCIT large detonation tube [55]: (a) transducer 1, (b) transducer 2, and (c) transducer 3 [35]

pressure gauges mounted in tube walls, resulting in artifacts (precursors and superimposed oscillations) in the pressure signals that can be quite significant in some cases [56].

3.3 Straight Tubes. The simplest situation is a detonation initiated at one end of a long tube, resulting in a close approximation to the idealized pressure field shown in Fig. 3. A typical set of pressure measurements made at three locations is given in Fig. 4. The negative values of pressure observed at long times on gauges 1 and 2 are artifacts due to the thermal response of the gauges to the hot gases in the detonation products. The typical experimental configuration [55] used in the laboratory at Caltech is shown in Fig. 5. The tube is made of up of three sections $2.3 \mathrm{~m}$ long, each with the properties shown in column 2 of Table 2 . The tube was instrumented with piezoelectric pressure transducers and bonded strain gauges (oriented to measure the hoop component) [35].

Strain signals from gauge 10 (located at $4.5 \mathrm{~m}$ from the initiation end, close to the axial location of transducer 2) are shown in Fig. 6 for three detonation velocities bracketing the first critical speed of $1455 \mathrm{~m} / \mathrm{s}$. The main signal is coincident with the arrival of the detonation at the measurement location and shows characteristic oscillations with a frequency of close to $5 \mathrm{kHz}$. For the high-speed wave, Fig. 6(c), a high-frequency precursor is visible. The existence of the precursor and the frequency content can be seen more clearly in Fig. 7(a). The lower branch of the dispersion relation corresponds to the main oscillations at $\sim f_{\text {hoop }}$ and the upper branch corresponds to the high-frequency precursor wave. The detailed features of the waveforms in Fig. 6 are determined by the interactions of the flexural waves with the tube flanges; interference between the incident and reflected waves produces the amplitude modulation and beating observed in these records.

In order to discuss the amplitude of the signals and determine if there are any resonance effects, we need to normalize the signals in order to eliminate the effects of different detonation pressures 


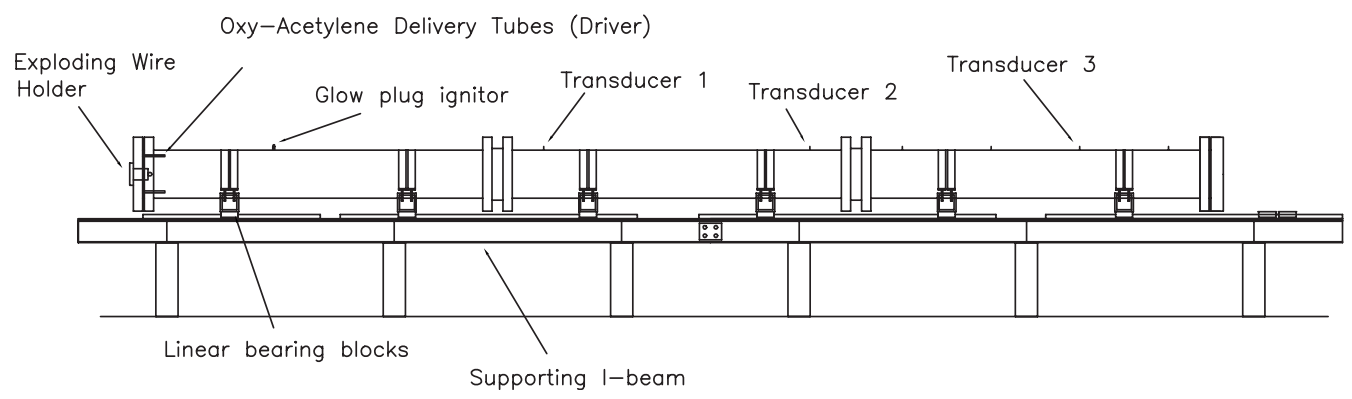

Fig. 5 The GALCIT large detonation tube facility [55]

for the different velocities. The normalized elastic response is usually defined in terms of the dynamic amplification or load factor. The dynamic amplification factor is defined as the ratio between the maximum dynamic strain and the equivalent static strain calculated from static formulas using the measured peak applied pressure

$$
\Phi=\frac{\epsilon_{\text {dynamic_max }}}{\epsilon_{\text {static }}}
$$

Since the measured pressure is subject to substantial fluctuations, the static strain is computed using the calculated value of $P_{\mathrm{CJ}}$ as long as the detonation appears to be ideal, i.e., wave speed close to $U_{\mathrm{CJ}}$. For a thin tube that is sufficiently long to be considered axially unconstrained, the static strain will be given by

$$
\epsilon_{\text {static }}=\sigma_{\theta} \frac{1-\nu^{2}}{E}
$$

where the hoop stress is related to the pressure difference by the simple membrane expression

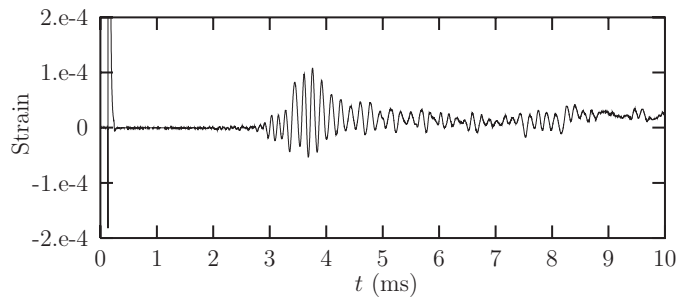

(a)

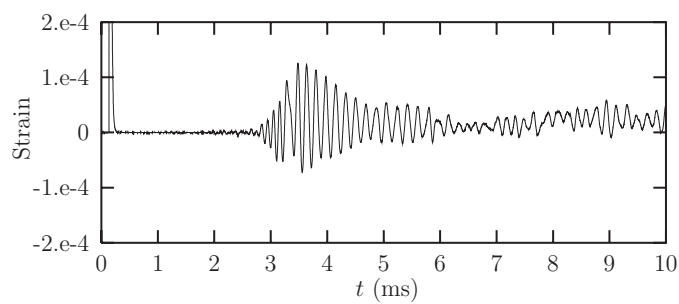

(b)

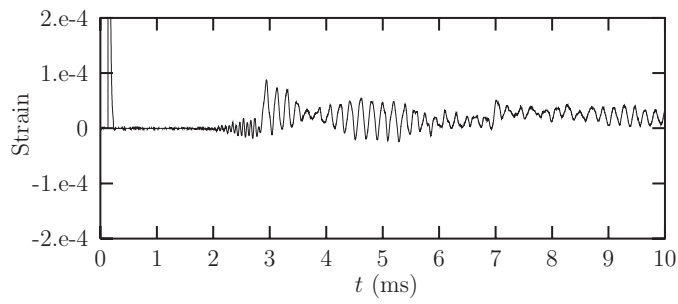

(c)

Fig. 6 Measured strain signals [35] from gauge 10 for three detonation velocities propagating at (a) $1400 \mathrm{~m} / \mathrm{s}$, (b) $1478 \mathrm{~m} / \mathrm{s}$, and $(c) 1700 \mathrm{~m} / \mathrm{s}$

$$
\sigma_{\theta}=\frac{R}{h} \Delta P_{\mathrm{CJ}}
$$

For thick tubes, the Lamé expressions should be used instead of the membrane model.

The amplification factor is plotted for gauge 10 as a function of the detonation wave speed in Fig. 7(b). The critical velocity for the Graduate Aeronautical Laboratories, California Institute of Technology (GALCIT) detonation tube is computed to be 1455 $\mathrm{m} / \mathrm{s}$ in reasonable agreement with the measured peak in the amplification factor. The amplification factor goes from about 1 below $V_{c 0}$, increases to a maximum of 3.5 near $V_{c 0}$, and drops to about 2 above $V_{c 0}$. The existence of a resonance at $U_{\mathrm{CJ}} \approx V_{c 0}$ is clearly shown by these results. The general features of the wave speed dependence are captured by both the Tang and finite element method (FEM) models but the FEM model with clamped end conditions (corresponding to rigid flanges) gives the best agreement for this tube. Note that the Tang theory is for a steadystate propagation, which assumes that all transient effects have died out, corresponding to a "large" distance of propagation. In addition, the results shown in Fig. 7 are close to the step-loading regime with the duration of the Taylor wave comparable to or larger than the hoop oscillation period. Just as in the singledegree-of-freedom, the response predicted by the Tang model will depend on the duration of the Taylor wave and the peak deformations will decrease with decreasing Taylor wave duration, reach-
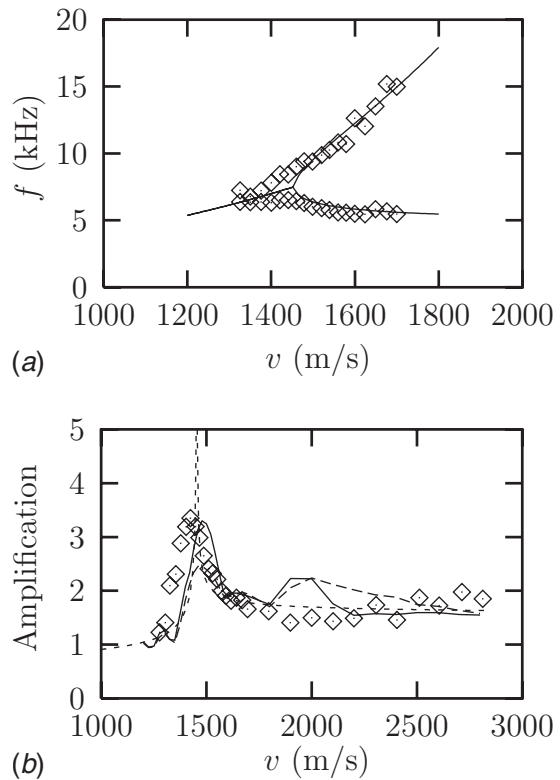

Fig. 7 Analysis of strain signals from gauge 10: (a) frequency content compared with Tang model and $(b)$ amplification factor from experiments $\diamond$ compared with Tang-and finite element models with simply-supported-and clamped ends [35] 


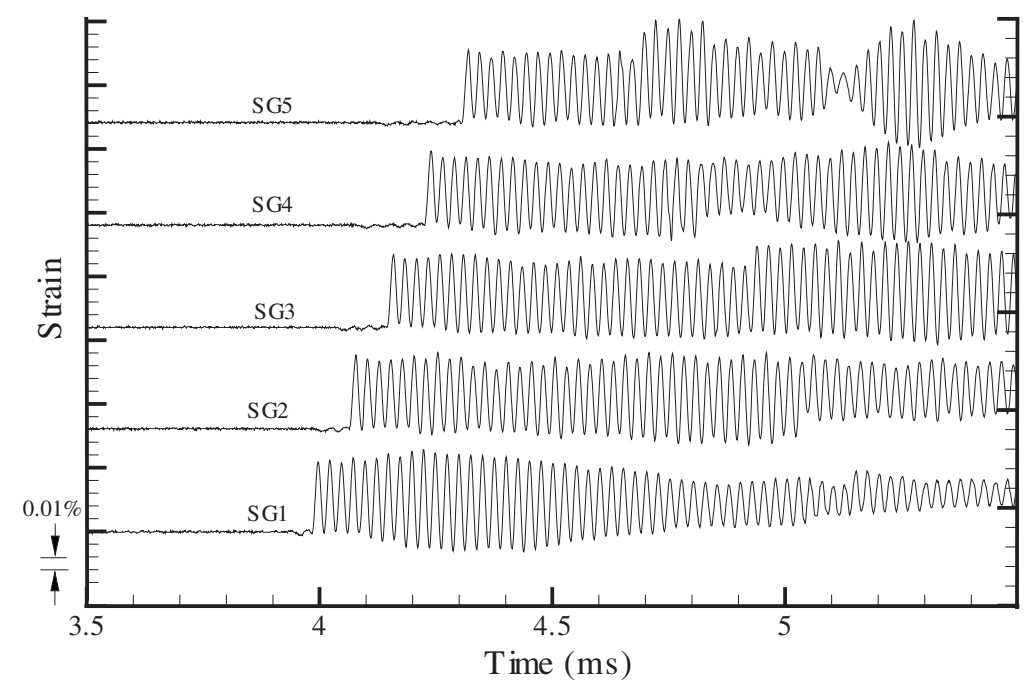

Fig. 8 Measured strain signals for a detonation propagating at $2841 \mathrm{~m} / \mathrm{s}$ in a $40 \mathrm{~mm}$ diameter Al specimen [56]

ing a limiting value corresponding to step loading at the plateau pressure $P_{3}$, see Ref. [35]. To include transient effects and account for the Taylor wave duration, FEM solutions should be performed [35] with a loading function that corresponds precisely to the situation being examined. The evolution of the peak strain amplitude with distance is predicted to be slowest for wave speeds close to $V_{c 0}$, and this is observed in the experiments, which are in reasonable quantitative agreement with the FEM model.

Further experiments were carried out with thinner tubes and higher wave speeds by Chao and Shepherd [56] and Chao [57] in order to examine the possibility of resonance at the second critical speed and also obtain strain signals that would not be contaminated by flange effects. Five strain gauges were located in the center of a $1.5 \mathrm{~mm}$ thick, $40 \mathrm{~mm}$ diameter aluminum tube specimen that was $1.5 \mathrm{~m}$ long (column 1 in Table 2). Detonations were initiated in a separate thick-wall section $1.5 \mathrm{~m}$ long and connected to the specimen by slip-on connections. $\mathrm{H}_{2}-\mathrm{O}_{2}$ mixtures diluted with helium were used to create detonations with speeds up to $3600 \mathrm{~m} / \mathrm{s}$. An example of the strain gauge measurements is shown in Fig. 8. The resulting dynamic load factors are shown in Fig. 9. From these results it is clear that there is no resonance in hoop strain when the detonation speed is equal to either $V_{c 1}$ or $c_{s}$. Numerical simulations of a finite element model implemented in LSDYNA (Livermore Software Technology Corp., Livermore, CA) revealed that a resonant response in the shear strain was predicted but since dynamic transverse shear strain of a tube cannot be measured by any known metrology, this effect cannot be observed in experiments.

After carrying out these experiments, careful quantitative comparisons [58] were made of the measured and computed strains. Despite our best efforts, we were unable to get agreement to within better than about $15-20 \%$ for the peak amplitude of the hoop strains. Through repeated trials, we were finally able to determine that there were two sources of systematic error in our measurements. First, the specimen tube wall thickness varied around the circumference of about $13 \%$. Second, the strain gauges showed shot-to-shot variation and evidence of microcracking causing artifacts in the signals. The strain measurements were

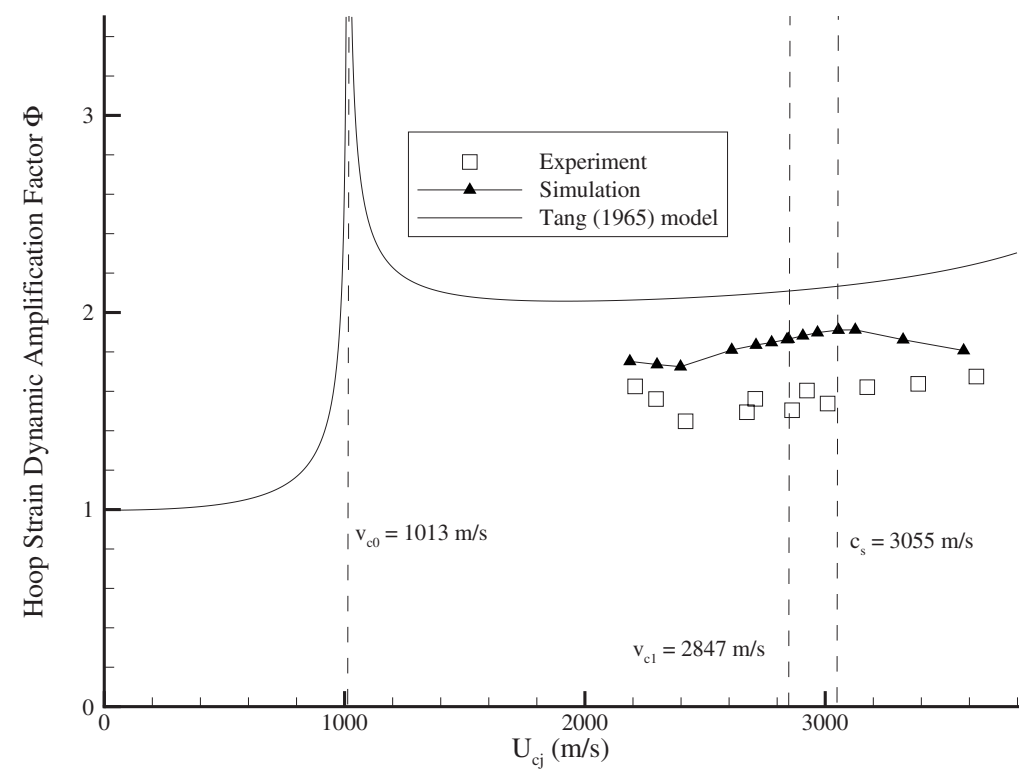

Fig. 9 Predicted and measured strain amplification factors for detonations propagating in a $40 \mathrm{~mm}$ diameter Al specimen [56] 

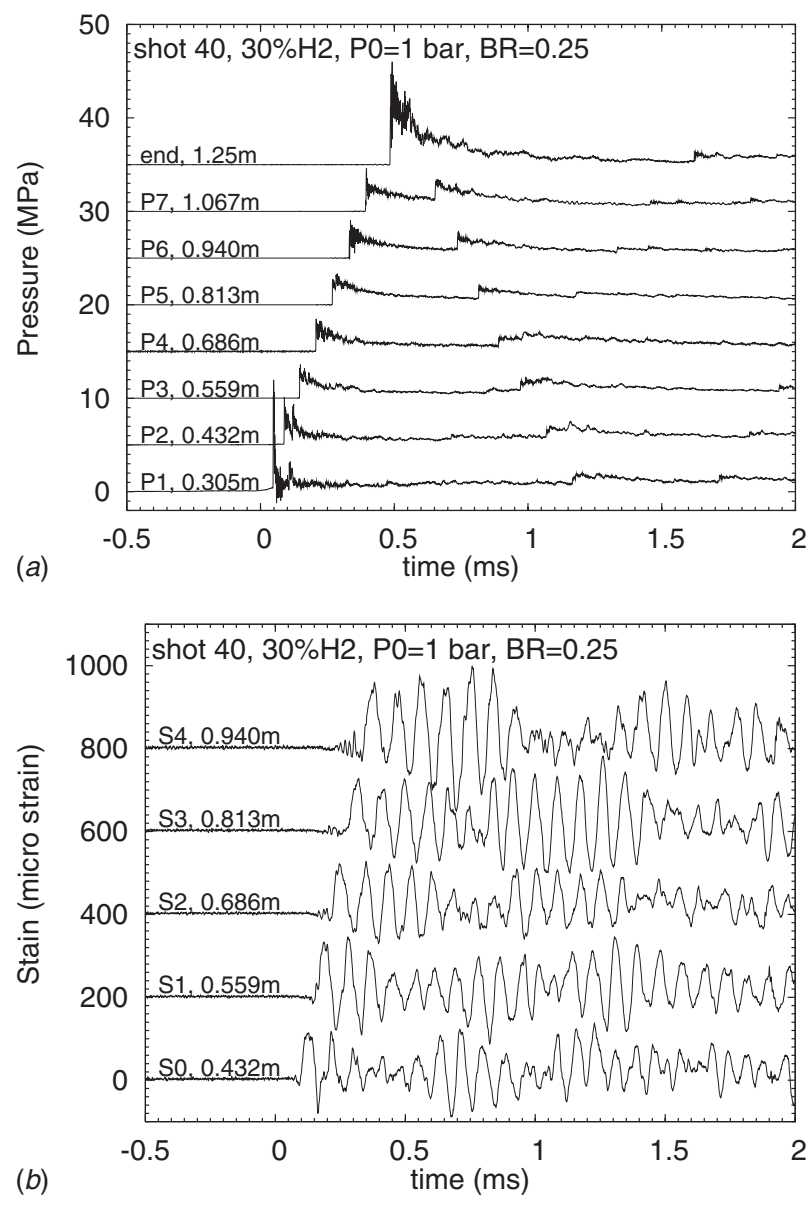

Fig. 10 Detonation propagation (rapid DDT near ignition point) and reflection from a closed end: (a) pressure measurements and (b) strain measurements [63]

repeated using an optical vibrometer in addition to the strain gauges, and the results were much more satisfactory [58]. A series of replica tests demonstrated that the detonation process and the vibrometer measurements were very repeatable with a shot-toshot variation of about $\pm 2 \%$. The measured detonation pressure and velocity were highly reproducible (within $0.5 \%$ ) but there is significant high-frequency structure in the pressure signal. Modeling the wall thickness variation and making comparisons with the vibrometer measurements [58] instead of the bonded strain gauges, elastic wave propagation simulations $[59,60]$ based on approximations to the experimental pressure loading [61] were able to predict the precursor and main wave profile in correct phase and also the peak strain amplitudes were predicted within $7 \%$.

3.4 Tubes With Closed Ends. As part of the study by Beltman and Shepherd [35], measurements were near the closed end of the tube and more recently, we have examined this situation using other facilities. When the detonation reaches a closed end, it will reflect as a shock wave that propagates away from the closed end. The peak pressure of the reflected shock wave [62] is about $2.5 P_{\mathrm{CJ}}$, and the pressure decays as the wave moves away from the reflecting surface. The reflected shock wave will induce flexural waves in the pipe, which will interfere with the waves that were created by the incident wave. An example of this is shown in Fig. 10 for a detonation initiated in $\mathrm{H}_{2}-\mathrm{N}_{2} \mathrm{O}$ mixture within a $316 \mathrm{~L}$ SS tube of $70 \mathrm{~mm}$ radius and $12 \mathrm{~mm}$ wall thickness [63]. The mixture was initiated by a spark but rapidly transitioned to a detonation due to the presence of periodic obstacles, which generated turbulent flow, causing the flame to accelerate quickly. Although the flexural wave train created by the reflection is not distinct, the peak strains occur after the detonation wave has reflected. The peak dynamic load factor is $\Phi=3.1$ based on the CJ pressure of 2.6 MPa and the peak measured strain of $197 \mu$. This is an increase of $50 \%$ due to the reflection process. If we base the dynamic load factor on the computed peak reflected shock pressure of 6.46 $\mathrm{MPa}$, then $\Phi=1.1$. However, no strain gauges were located closer than $0.31 \mathrm{~m}$ from the end wall so that the measured peak strains are smaller due to the attenuation of the shock as it travels away from the end wall.

3.5 Tubes With Bends and Tees. Process plant piping is characterized by straight runs of pipe connected by elbows, tees, valves, pumps, reactor vessels, holding tanks, and other features, including detonation and flame arrestors. In addition, the piping system is suspended or supported from a framework that provides reaction forces and limits the motion of the piping. If detonations are possible within the piping, then a comprehensive analysis of the structural response requires considering how the detonation will interact with these features and what structural loads will be created. One generic situation is the dead-end (closed valve or blank-off flange) that was considered previously. Another is the elbow or tee connection. Detonation propagation through an elbow or tee is an example of detonation diffraction [64], which, depending on the direction of curvature, may cause the detonation to intensify or weaken [65]. In general, the situation is quite complex since combinations of these features occur in various parts of a processing plant. Thomas [53] carried out experiments on simple models of plastic piping runs measuring both the forces on the supports and the strains on the pipes. Liang et al. [66,67] made measurements of strains and pressures in small-scale specimens of thin-wall metal tubing containing $90 \mathrm{deg}$ bends and tees. These studies show that it is feasible to obtain useful data on these complex problems but it is necessary to consider a wide range of time scales since the motion of the supports occurs over a time of $0.1-1$ $\mathrm{s}$ while the deformation due to flexural waves occurs on a submillisecond time scale. Substantial motion of the pipe supports was observed in the Thomas tests, raising the possibility of piping containing the explosion at early times but failing due to excessive distortion of the supports.

3.6 Rupture of Tubes. Recently, two failures occurred in piping systems in nuclear power plants that have prompted examination of failure mechanisms due to detonation loading. On November 7, 2001, the Hamaoka-1 NPP in Japan suffered a pipeline rupture accident, apparently due to the detonation of a hydrogenoxygen mixture that accumulated due to radiolysis $[7,68]$. The Brunsbüttel KBB in Germany had similar failure [5] on December 14,2001 . In both cases, the tubes were observed to have multiple fractures and fragmentation occurred, see Fig. 11. The detailed analyses carried out after these accidents showed that the failures could be explained by excessive deformation (hoop strains of 23 $27 \%$ ) caused by the pressure loading of a detonation propagating in radiolysis products at 70 bar initial pressure.

Although similar failures can be produced in the laboratory with sufficiently thin tubing or high internal pressure, it is difficult to study the failure mechanisms in detail without pre-existing flaws to create reproducible fracture initiation sites. The issues of fracture threshold, crack propagation speeds, crack branching, and the effect of prestress have been examined by Chao [57] and Chao and Shepherd $[69,70]$ for thin-walled aluminum specimens with coin-shaped axial flaws partly through the tube wall, for example, see Fig. 12. For a given tube, flaw, and internal pressure, the crack propagation and resulting tube deformation are quite different for hydrostatic, pneumatic, and detonation loading due to the very different amount of energy stored in these cases. Paradoxically, static pressurization with gas (pneumatic case) creates a greater crack driving force than using a detonation wave when the gas pressure is equal to the CJ value [70]. This is due to the elastic energy stored in the prestressed tube and the lower sound speed in 


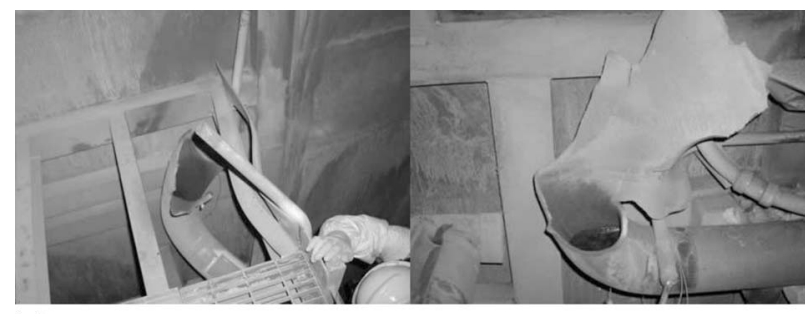

(a)

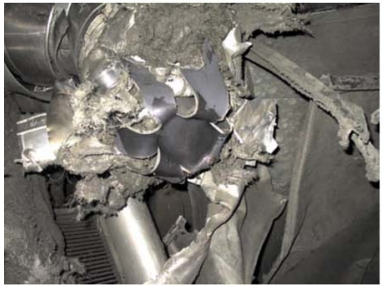

(b)

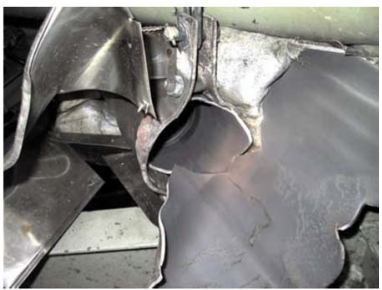

(c)

Fig. 11 Pipe rupture due to overpressure by explosions: (a) Hamaoka-1 NPP [7] and (b) Brunsbüttel KBB [5]

the cold gas versus the hot detonation products. Since even the slowest gaseous detonations rapidly outrun even the fastest propagating cracks (the highest crack tip speeds we observed were less than $350 \mathrm{~m} / \mathrm{s}$ ), for practical structural analysis and simulations in gaseous detonation-fracture interaction, the influence of the venting on the chemical kinetics within the detonation front appears to be negligible.

Dramatic differences between plastic and metal tubes are observed $[71,50,53]$ in elastic response and fracture because detonation waves are typically much (up to an order of magnitude) faster than any of the critical or characteristic speeds and significant visco-elastic effects can occur. For example, in polycarbonate tubes, only very limited oscillatory deformation was observed in hoop and axial directions with gradual increase in strain leading to a single (axial) or double (hoop) peak followed by a monotonic decay to a constant strain in the hoop direction. Observations in both PVC [50] and GRP [53] showed a fast precursor in the longitudinal strain and rapid damping of the oscillations, and in PVC, a residual hoop strain. The peak amplitude of the deformations observed in PVC was significantly smaller than predicted by the single-degree-of-freedom model with an ideal detonation loading

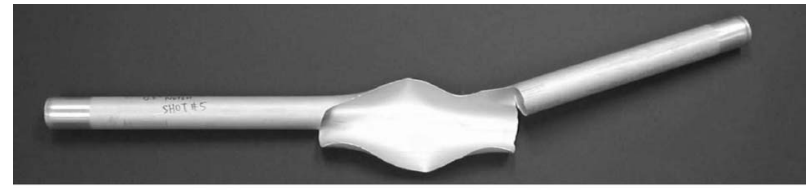

(a)

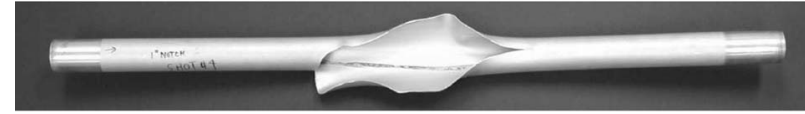

(b)

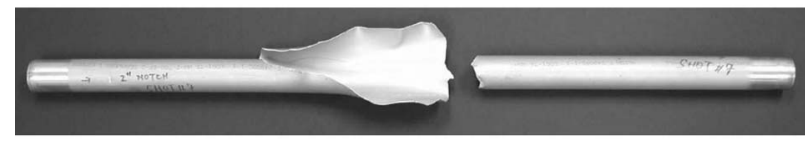

(c)

Fig. 12 Thin-wall (column 1 of Table 2) tubes with pre-existing flaws; rupture due to propagating detonations [69]: (a) $12.7 \mathrm{~mm}$ long flaw, (b) $25.4 \mathrm{~mm}$ long flaw, and (c) $50.8 \mathrm{~mm}$ long flaw profile, leading Brossard and Renard [50] to speculate about the possible importance of coupling between the flexural motion and detonation process.

Fracture thresholds and crack propagation in plastics can also be expected to be quite different than in metals due to the much lower (by up to an order of magnitude) yield strength and fracture toughness as well as the wide range of fracture types. Polycarbonate tubes usually exhibited [71] a straight crack that propagated upstream and downstream from the flaw before running in a helical fashion around the tubes, similar to behavior observed for aluminum tubes. In acrylic tubes [71], the dominant fracture pattern was the catastrophic fragmentation, with a possible correlation between fragment size and number with detonation load strength. PVC [72] and MDPE [53] also rupture in a brittle fashion if the wall is sufficiently thin or the detonation pressure sufficiently high. Thomas [53] reported that GRP was "remarkably resilient" with no failures observed in his trials.

A simple fracture criterion for detonation loading of preflawed tubes has been developed [69] based on linear elastic fracture mechanics, the critical stress intensity factor, and treating the flaw as a surface crack in a wide plate under far field tension. The magnitude of the tension is obtained from the strain field predicted by the Tang model of tube response to the detonation load for tubes without prestress. Experiments with various flaw depths and lengths in aluminum tubes show a reasonable agreement between the predicted fracture threshold and the observed structural failure. Limited data on polycarbonate tubes [71] indicate that the fracture threshold is substantially underpredicted by the model.

The effect of torsional prestress on crack paths in aluminum tubes was also studied [57]. By applying torsion, the initial crack path could be altered and the crack kinking angle could be correlated with the mode mixity (the ratio of the stress intensity factors for mode I and mode II loading). Visual observations of the crack motion (Fig. 13) and strain measurements revealed a significant influence of the shear waves created by the release of the torsion upon crack initiation.

\section{Deflagration-to-Detonation Transition Loads}

It has been known for some time $[73,74]$ that DDT can produce pressures in excess of the CJ or reflected CJ pressure. White [73] reported observations of reflected pressures in stoichiometric $\mathrm{H}_{2}$-air initially at $300 \mathrm{~K}$ and $1 \mathrm{~atm}$. During flame acceleration in a $3.5 \times 3.5$ in. $(89 \mathrm{~mm} \times 89 \mathrm{~mm})$ tube $32 \mathrm{ft}(9.75 \mathrm{~m})$ long, a peak pressure of $170 \mathrm{~atm}$ was recorded. This is 4.5 times the usual reflected CJ pressure and is probably due to the overdriven detonation produced during the transition process. As discussed previously, reflected pressures of this magnitude can be produced by a detonation that is $20 \%$ faster than a CJ detonation. Our computations indicate that such overdriven detonations can be readily generated during the transition process and persist for some time afterward. The tube used by White was not damaged since it was a very robust design.

Craven and Grieg [74] reported the production of high pressures during DDT events in ammonia-nitrous oxide mixtures. Static pressures up to $70 \mathrm{~atm}$ in the transition region (the ideal CJ pressure $P_{\mathrm{CJ}}=30$ atm for this mixture) were recorded. More significant reflected pressures up to $340 \mathrm{~atm}$ were inferred (the ideal reflected CJ pressure $P_{R}=71$ atm for this mixture) from the deformation of the end plate. These pressures were not actually measured. Moreover, the velocities reported by Craven and Grieg were recorded in separate experiments without an end plate. The relation between inferred pressure and wave velocity plays a key role in their conclusions but appears suspect.

The very high pressures were only obtained when the transition was arranged to occur near the closed end of the tube. However, it is not clear if the dynamic load factor was properly accounted for in these tests. Craven and Grieg did not give any discussion of the structural dynamics. This is a serious problem since pressures were determined from deformation of a sacrificial end plate rather 


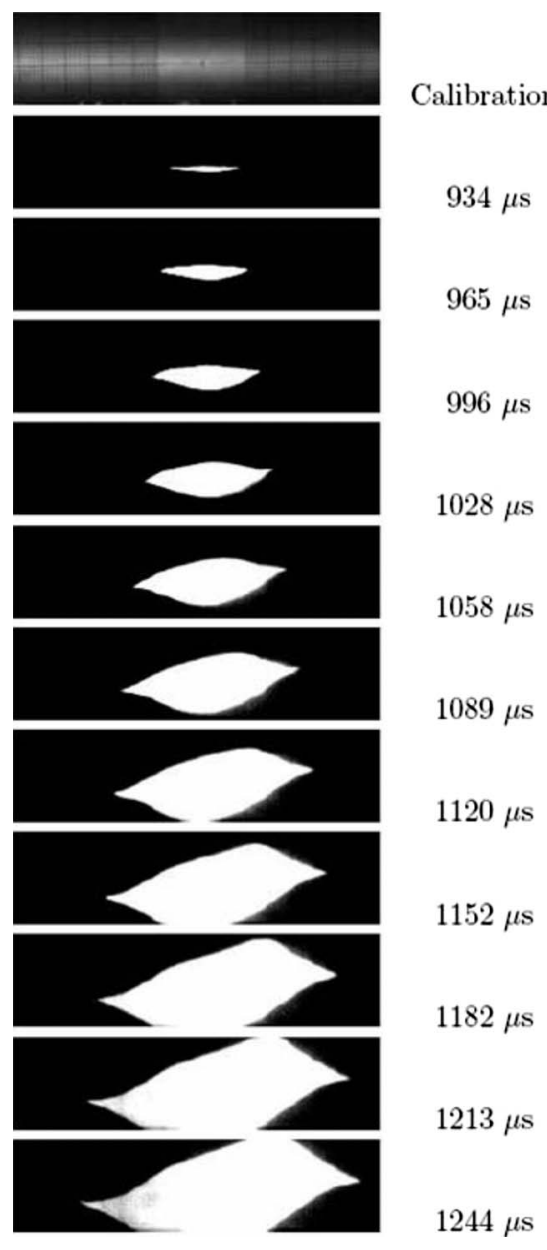

Fig. 13 Crack opening and propagation in thin-wall (column 1 of Table 2) tube under torsion with a pre-existing flaw and detonation loading [57]

than pressure transducers. Despite the relative weakness of the tube used by Craven and Grieg, no failure of the tube itself was noted.

Craven and Greig speculated that these pressures were created when the detonation occurred within the shocked gas ahead of the flame. They proposed a "double discontinuity" model consisting of a detonation behind a shock. Their shock interaction calculations suggested that this model could easily account for the magnitude of the pressure waves produced in detonation reflection. They obtained calculated peak reflected pressures between 340 atm and $880 \mathrm{~atm}$. However, these extreme values were based on an idealized interaction for the detonation and shock merging just as the end of the tube was reached. These pressures represent extreme upper bounds that may only be achieved in exceptional cases.

Unsteady gas dynamic computations [75] indicate that the pressures observed by Craven and Greig could, in fact, be produced by some variation in multiple detonation-shock interactions. Thermochemical computations and simulations [75] yield similar bounds on the peak pressures of $350-540 P_{o}$ for the case of $\mathrm{H}_{2}$-air mixtures. However, a very special set of circumstances is required to produce these pressures. Values in the range of $150 P_{o}$, as observed by White and computed in the simulations, appear to be more likely.

The experimental evidence that DDT can result in pressures much higher than direct initiation of detonation is reviewed by Thibault et al. [3]. The basic notion, as discussed above, is that the flame precompresses the mixture prior to the onset of detonation.
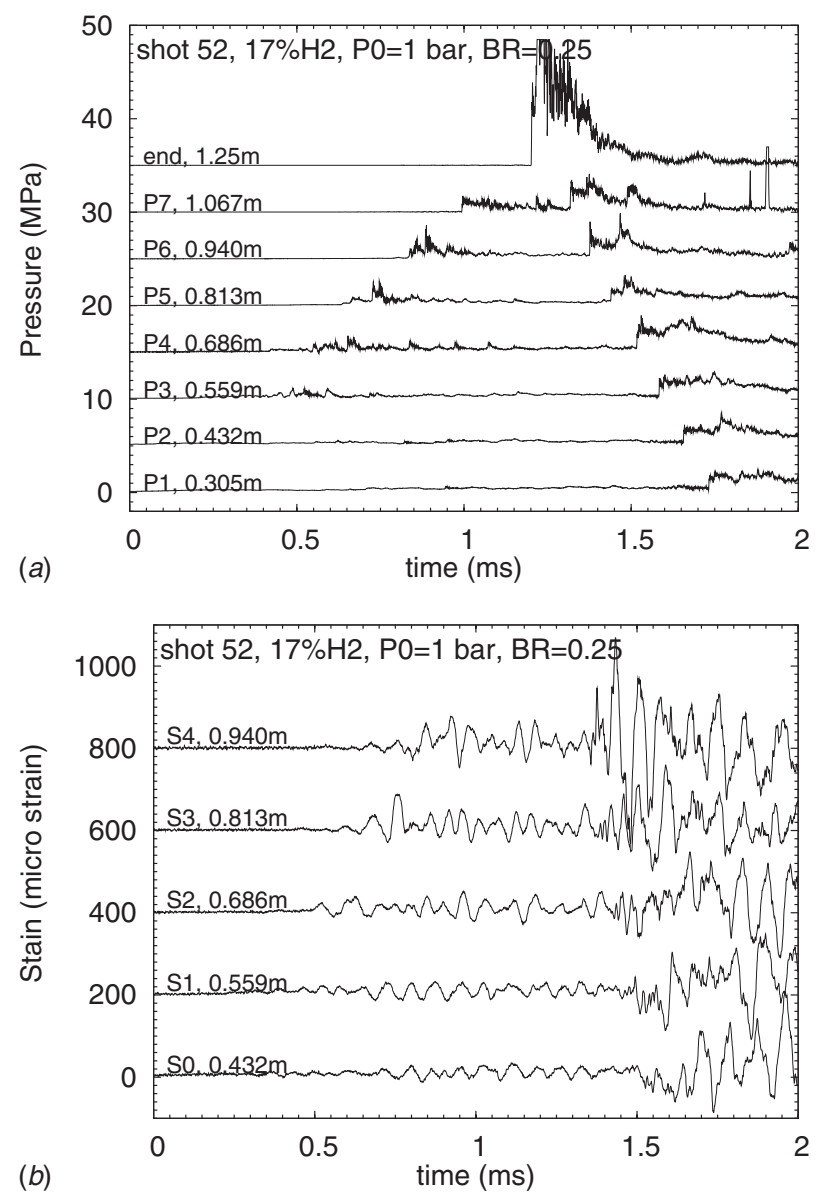

Fig. 14 Deflagration-to-detonation transition near a closed end: (a) pressure measurements and (b) strain measurements [63]

This is sometimes referred to as "pressure piling" in the process industry. Transition to detonation in this precompressed mixture results in much higher detonation pressures, and consequently pressures created by the detonation reflection, than if CJ detonation has simply reflected from the end of the tube. The worst case situation that was identified by Craven and Greig involves transition to detonation within the gas processed by the reflected shock produced by a fast flame. Numerical simulations $[76,75]$ indicate that the peak pressure created by such an event can be up to an order of magnitude higher than the CJ detonation pressure. An example of an experimental measurement of such an event is shown in Fig. 14 for a detonation initiated in a $\mathrm{H}_{2}-\mathrm{N}_{2} \mathrm{O}$ mixture within a $316 \mathrm{~L}$ SS tube of $70 \mathrm{~mm}$ radius and $12 \mathrm{~mm}$ wall thickness. The mixture was initiated by a spark and transition to detonation did not occur until the last $0.25 \mathrm{~m}$ of the tube. A precursor shock wave is clearly visible at transducer P7 but not at the end wall. The peak pressure at the end wall was so high that it saturated the transducer, and a large-amplitude flexural wave associated with the reflected shock wave can be observed propagating away from the end wall after transition has taken place. The peak strain was $270 \mu$ and based on the CJ pressure of $2.5 \mathrm{MPa}$, the dynamic load factor was $\Phi=4.4$ at a location $0.3 \mathrm{~m}$ away from the end wall.

This type of extreme situation, DDT within shock compressed gas, has been observed in laboratory tests by many others, including Refs. [77-79,3]. Kogarko carried out initiation and critical tube testing and observed that attempts to initiate insensitive mixtures with detonations very often resulted in rapid flame propagation and DDT. Very high pressures, up to 347 bars, were measured at the closed end of the tube in methane-oxygen-nitrogen experi- 
ments. Kogarko's tube (305 mm diameter, $10 \mathrm{~mm}$ wall thickness) was destroyed by a DDT event in a mixture with $6.8 \%$ acetylene in air. A critical tube experiment was being carried out, the detonation failed, and an accelerating flame was produced with velocities up to $880 \mathrm{~m} / \mathrm{s}$. The consequences were dramatic: "At the end of the tube there arose, to all appearances, a pressure which was exceedingly high, and which acted over a period of time, as a result of which the end section of the steel tube was demolished with heavy fragments flying out in all directions (the end cap, flange, valve, etc.). The tube rupture was accompanied by an extremely powerful sound effect. It should be noted that in a large number of experiments involving the detonation of methane-air mixtures, in which the pressure in the tube was over $200 \mathrm{~kg} / \mathrm{cm}^{2}$, some sort of mechanical alterations in the end section was not observed." [77]. Note that $1 \mathrm{~kg} / \mathrm{cm}^{2}$ is equal to 0.981 bar. A series of experiments in propane-air was carried out to measure the peak pressures in more detail. For a stoichiometric mixture at an initial pressure of 1 bar, the maximum pressure was an average of 461 bars over a time of $4 \mu$ s following reflection.

Chan and Dewitt [78] measured pressures ahead of a "choked" flame that were up to a factor of 3 higher than the initial pressure. In Ref. [79], a peak reflected pressure of 250 bars was observed for a hydrocarbon-air mixture at an initial pressure of 1 bar. In Ref. [3], DDT was observed during flame acceleration tests in pure ethylene oxide, and they computed that the peak pressure could have been as high as 140 times the initial pressure due to precompression.

\section{Plastic Deformation Response}

For pressure vessels or tubes in the plastic deformation regime, catastrophic failure associated with ductile tearing or plastic instability is usually termed "rupture." For static loading this occurs at the burst pressure [15], which depends crucially on the details of the ductility of the material. For dynamic loading, the situation is considerably more complex and depends on the details of the pressure waveform [10] and not just the peak pressure. For highductility steels like those used in the present study, substantial deformation and energy absorption can take place in the process of stretching the material up to the point of rupture.

Duffey et al. [15] suggested that for dynamic loads it is this ability of a structure to absorb energy through plastic deformation that is most important in designing fracture safe vessels to contain explosive loading. Therefore, they proposed that design criteria based on specifying safe levels of plastic strain are most relevant. For certain metals, plastic strains of up to $28 \%$ are observed without rupture although we are certainly not advocating this as a design limit. An extensive discussion of proposed ductile failure criteria is given by Duffey et al. [15].

In a static loading situation, the onset of plastic behavior in the wall of a pressure vessel occurs when the internal pressure exceeds a critical value, $P_{y}$ and at a somewhat higher pressure, $P_{p}$, the entire vessel wall will be in a state of plastic deformation. If the material exhibits significant strain hardening, then the pressure that results in the onset of the yielding for a structure can be substantially lower than the pressure $P_{\text {burst }}$ that results in rupture or burst of the vessel.

In a dynamic loading situation, it is more useful to focus on the peak deformations than the pressures. For elastic analyses, we introduced the concept of dynamic load factor and used this to estimate peak deformations for a given waveform and peak pressure. For plastic analyses, the details of the waveform are more important than in the elastic case and it is necessary to consider the motion of the material up to the onset of yielding, the duration of the plastic deformation period, and the subsequent elastic oscillations once plastic deformation has ceased.

In order to model plastic deformation, there are key issues that must be addressed. One is the material model-the appropriate description of both strain-hardening and strain-rate effects must be included. Another is that the loading history must be known. Al- though it is sufficient in elastic analysis to specify a dynamic load factor and peak pressure, this is not adequate for a plastic analysis. Finally, nonlinear finite element methods are usually required in order to handle spatially distributed loads and the large deformations that may occur in the plastic regime. In some cases, useful results and guidance for the FEM modeling can be obtained from the single-degree-of-freedom model $[80-85,10]$. Under certain assumptions and loading regimes, analytical solutions are possible; a typical approximation [81] is to neglect the axial stress resultant and bending moment, consistent with a purely radial motion. Comparison of one- and two-dimensional solutions [86] shows that as long as the load is approximately uniform over an axial distance exceeding (see Table 2)

$$
X_{\lambda}=\left(\frac{R^{2} h^{2}}{3\left(1-\nu^{2}\right)}\right)^{1 / 4}
$$

then the single-degree-of-freedom model gives a reasonable estimate for the maximum deflection. These models show reasonable agreement with high explosive experiments for which the loading can be approximated as impulsive and localized spatially, i.e., not a traveling load. These models can be used to estimate maximum deformation in the case of gas explosions, resulting in DDT near a closed end, for example, as shown in Fig. 15.

It is possible to observe $[88,87]$ permanent deformation due to propagating and reflected $\mathrm{CJ}$ detonations. For very ductile metals (for example, dead-soft copper) and detonation peak pressures sufficient to cause yielding but not rupture, plastic deformation waves can be observed [88] to propagate in phase with the detonation front. Measurements of strain [87] due to CJ detonations propagating in thin-wall steel tubes (column 3 of Table 2) under this condition show a mixed plastic-elastic response with elastic oscillations of small amplitude superimposed on the permanent plastic deformation. Single-degree-of-freedom simulations of strain resulting from propagating detonations give reasonable agreement with the observed peak deformation as long as both strain-rate and strain-hardening effects are included in the constitutive relationship. An additional increment of plastic deformation is produced in this loading regime when the detonation reflects from a closed end. In contrast to the DDT case shown in Fig. 15, the maximum plastic strain is only about $2 \%$ due to a reflected CJ detonation in a mixture with comparable CJ properties (a CJ pressure of 110 bars). This confirms the very significant role that DDT can play in structural loading.

\section{Conclusions}

The structural response to detonations inside pipes and tubes has been studied using experiments, analytical methods, and numerical simulation. The elastic response depends strongly on the detonation speed as compared with the first critical speed, the flexural wave group velocity, $V_{c 0}$. For $U_{\mathrm{CJ}}<V_{c 0}$, the dynamic load factor $\Phi \approx 1$; for $U_{\mathrm{CJ}}>V_{c 0}$, the dynamic load factor $\Phi \approx 2$. For $U_{\mathrm{CJ}} \approx V_{c 0}$, resonance occurs and $\Phi$ can reach values as large as 4 . The critical velocity concept may be important for design and analysis if the wave speeds overlap the critical speeds. Finite element simulations of the structural response showed fair agreement with the measurements and were able to predict the transient development of the profile. Measurements indicate that flanges have a significant influence on the tube response, and the reflection and interference of flexural waves lead to higher strains. Measurements with different mixtures show that when the cell size and the structural wavelength are of the same order of magnitude, the flexural waves are excited particularly well. This led to the highest amplification factor $(\Phi=4)$ measured [35]. Detonation interaction with piping components such as dead ends, tees, and elbows can result in significantly higher and lower pressures than propagation within straight piping runs. Experiments have demonstrated that substantial loads and deflections can be generated in supporting structures due to detonations in piping runs. Rupture of pipes due to internal detonations has been observed in a number 


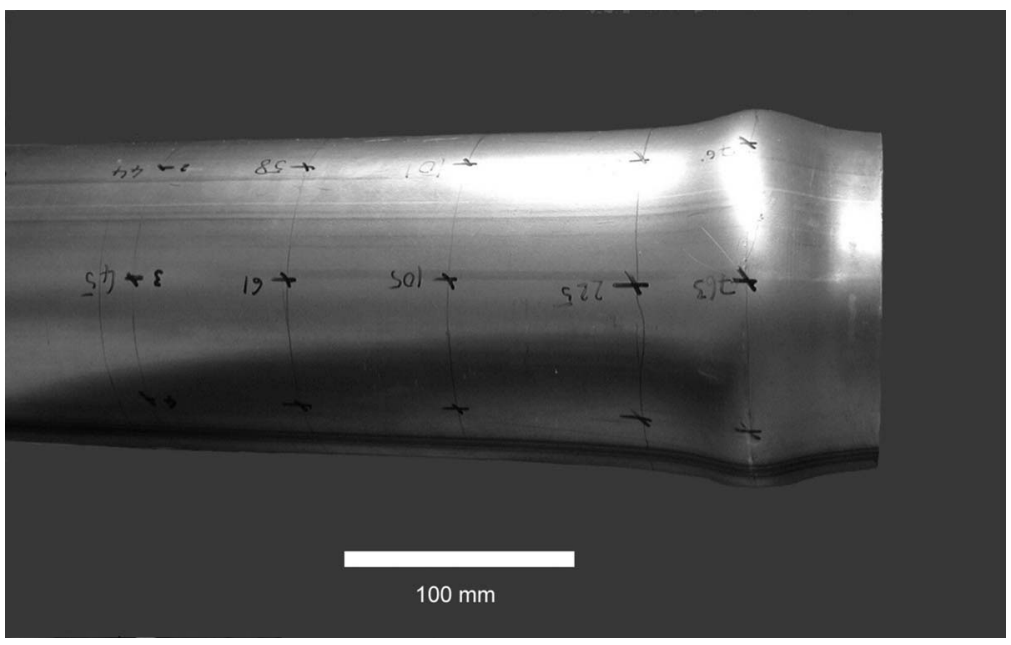

Fig. 15 Plastic deformation of $15 \%$ produced in a thin-wall tube (column 3 of Table 2) of mild steel by DDT next to closed end located at the right-hand side. The peak pressure measured at the end was approximately 500 bars twice the computed value for a reflected $\mathrm{CJ}$ detonation [87]

of situations. Particularly severe loads can occur if the transition to detonation takes place near the closed end of a tube. Realistic material models and loading histories are required in order to make quantitative predictions of plastic deformation. Strain-rate effects can be particularly important and difficult to accurately capture.

\section{Acknowledgment}

The results reported in this paper were obtained by a number of researchers working in my laboratories over the past decade. In particular, the bulk of the work was carried out by former students W. Beltman, T.-W. Chao (both now at Intel Corporation), and F. Pintgen (currently at GE Global Research, Nisakyuna, NY), and also current student J. Karnesky and former postdoctoral scholar Z. Liang, now at AECL, Chalk River. Term projects by students T. Curran, E. Burcsu, L. Zuhal, A. Lam, M. Zeilonka, M. Kozlowski, and A. Lew contributed important results. While working at the Caltech ASC Center, P. Hung, F. Cirak, and R. Dieterding all carried out simulations and contributed substantially to our understanding of how to design these experiments in order to carry out effective validation of simulations. Thanks to my solid mechanics colleagues W.G. Knauss, A.J. Rosakis, and G. Ravichandran for their helpful discussions and generous loans of instrumentation. This research was sponsored over the past decade by the U.S. Nuclear Regulatory Commission, by the Office of Naval Research (ONR), and by the U.S. DOE (NNSA) through the Caltech ASC project. Figures 1 and 3-7 reproduced by kind permission of Elsevier Publishing. Figures 8, 9, and 12 reproduced with kind permission of Springer Science and Business Media.

\section{References}

[1] Shepherd, J. E., 2008, "Detonation in Gases," Proceedings of the Combustion Symposium, Vol. 32

[2] Lee, J. H. S., 2008, The Detonation Phenomenon, Cambridge University Press, Cambridge.

[3] Thibault, P., Britton, L., and Zhang, F., 2000, "Deflagration and Detonation of Ethylene Oxide Vapor in Pipelines," Process Saf. Prog., 19(3), pp. 125-139.

[4] Grossel, S. S., 2002, Deflagration and Detonation Flame Arresters, Wiley, New York.

[5] Kuznetsov, M., Breitung, W., Grüne, J., and Singh, R. K., 2005, "Structural Response of DN15-Tubes Under Radiolysis Gas Detonation Loads for BWR Safety Applications," 18th International Conference on Structural Mechanics in Reactor Technology, Beijing, China, Paper No. SMiRT 18-J09-1.

[6] Krieg, R., Dolensky, B., Goller, B., Breitung, W., Redlinger, R., and Royl, P., 2003, "Assessment of the Load-Carrying Capacities of a Spherical Pressurized Water Reactor Steel Containment Under a Postulated Hydrogen Detonation," Nucl. Technol., 141(2), pp. 109-121.
[7] Naitoh, M., Kasahara, F., Kubota, R., and Ohshima, I., 2003, "Analysis of Pipe Rupture of Steam Condensation Line at Hamoaka-1, (I) Accumulation of Noncondensable Gas in a Pipe," J. Nucl. Sci. Technol., 40(12), pp. 1032-1040.

[8] OECD, 2000, "Flame Acceleration and Deflagration to Detonation Transition in Nuclear Safety," OECD Nuclear Energy Agency Technical Report No. NEA/CSNI/R(2000)7.

[9] Roy, G. D., Frolov, S. M., Borisov, A. A., and Netzer, D. W., 2004, "Pulse Detonation Propulsion: Challenges, Current Status, and Future Perspective," Prog. Energy Combust. Sci., 30, pp. 545-672.

[10] Florek, J. R., and Benaroya, H., 2005, "Pulse-Pressure Loading Effects on Aviation and General Engineering Structures," J. Sound Vib., 284, pp. 421453.

[11] Baker, W. E., Cox, P. A., Westine, P. S., Kulesz, J. J., and Strehlow, R. A., 1983, Explosion Hazards and Evaluation, Elsevier, Amsterdam.

[12] Bjerketvedt, D., Bakke, J. R., and van Wingerden, K., 1997, "Gas Explosion Handbook," J. Hazard. Mater., 52, pp. 1-150.

[13] NFPA, 2002, "Standard on Explosion Protection Systems," National Fire Protection Association Technical Report No. 69.

[14] ASME, 2008, "Case 2564-Impulsively Loaded Pressure Vessels," Supplement 4 of ASME B and PV Code Cases: Boilers and Pressure Vessels, The American Society of Mechanical Engineers, New York, NY.

[15] Duffey, T., Rodriguez, E., and Romero, C., 2002, "Design of Pressure Vessels for High-Strain Rate Loading: Dynamic Pressure and Failure Criteria,” Weld. Res. Counc. Bull., 477.

[16] Rodriguez, E., and Duffey, T., 2004, "Fracture-Safe and Fatigue Design Criteria for Detonation-Induced Pressure Loading in Containment Vessels," Weld Res. Counc. Bull., 494.

[17] Pellini, W., 1973, "Design Options for Selection of Fracture Control Procedures in the Modernization of Codes, Rules and Standards. Analytical Design Procedures for Metals of Elastic-Plastic and Plastic Fracture Properties," Weld. Res. Counc. Bull., 186.

[18] Ciccarelli, G., and Dorofeev, S., 2008, "Flame Acceleration and Transition to Detonation in Ducts," Prog. Energy Combust. Sci., 34(4), pp. 499-550.

[19] Fickett, W., and Davis, W. C., 2001, Detonation Theory and Experiment, Dover, New York.

[20] Tieszen, S. R., Stamps, D. W., Westbrook, C. K., and Pitz, W. J., 1991, "Gaseous Hydrocarbon-Air Detonations," Combust. Flame, 84(3), pp. 376-390.

[21] Shepherd, J. E., 1986, "Chemical Kinetics of Hydrogen-Air-Diluent Detonations," Prog. Astronaut. Aeronaut., 106, pp. 263-293.

[22] Westbrook, C. K., and Urtiew, P. A., 1982, "Chemical Kinetic Prediction of Critical Parameters in Gaseous Detonation," 19th Symposium on International Combustion Processes, pp. 615-623.

[23] Reynolds, W., 1986, "The Element Potential Method for Chemical Equilibrium Analysis: Implementation in the Interactive Program STANJAN," Mechanical Engineering Department, Stanford University, Technical Report.

[24] McBride, B., and Gordon, S., 1996, "Computer Program for Calculation of Complex Chemical Equilibrium Compositions and Applications: II. Users Manual and Program Description," NASA Reference Publication No. 1311.

[25] Browne, S., Ziegler, J., and Shepherd, J. E., 2004, "Numerical Solution Methods for Shock and Detonation Jump Conditions," Graduate Aeronautical Laboratories, California Institute of Technology, Technical Report No. FM2006.006

[26] Beltman, W., Burcsu, E., Shepherd, J., and Zuhal, L., 1999, "The Structural Response of Tubes to Internal Shock Loading," ASME J. Pressure Vessel Technol., 121, pp. 315-322.

[27] Stamps, D. W., Slezak, S. E., and Tieszen, S. R., 2006, "Observations of the 
Cellular Structure of Fuel-Air Detonations," Combust. Flame, 144(1-2), pp. 289-298.

[28] Pintgen, F., Austin, J. M., and Shepherd, J. E., 2003, "Detonation Front Structure: Variety and Characterization," Confined Detonations and Pulse Detonation Engines, G. Roy, S. Frolov, R. Santoro, and S. Tsyganov, eds., Torus, Moscow, pp. 105-116.

[29] Austin, J., 2003, “The Role of Instability in Gaseous Detonation,” Ph.D. thesis, California Institute of Technology, Pasadena, CA.

[30] Pintgen, F., 2004, "Detonation Diffraction in Mixtures With Various Degrees of Instability," Ph.D. thesis, California Institute of Technology, Pasadena, CA.

[31] Kaneshige, M., and Shepherd, J., 1997, "Detonation Database," GALCIT Technical Report No. FM97-8.

[32] Dorofeev, S., Sidorov, V., Kuznetsov, M., Matsukov, I., and Alekseev, V., 2000, "Effect of Scale on the Onset of Detonations," Shock Waves, 10(2), pp. 137-149.

[33] Taylor, G., 1950, "The Dynamics of Combustion Fronts Behind Plane and Spherical Detonations," Proc. R. Soc. London, Ser. A, 200, pp. 235-247.

[34] Zeldovich, Y. B., 1942, "On the Distribution of Pressure and Velocity in the Products of a Detonation Explosion, Specifically in the Case of Spherical Propagation of the Detonation Wave," J. Exp. Theor. Phys., 12(1), pp. 389406.

[35] Beltman, W., and Shepherd, J., 2002, "Linear Elastic Response of Tubes to Internal Detonation Loading," J. Sound Vib., 252(4), pp. 617-655.

[36] Radulescu, M., and Hanson, R., 2005, "Effect of Heat Loss on Pulse Detonation Engine Flow Fields and Performance," J. Propul. Power, 21(2), pp. 274 285.

[37] Edwards, D., Brown, D., Hooper, G., and Jones, A., 1970, "Influence of Wall Heat Transfer on Expansion Following a C-J Detonation Wave," J. Phys. D: Appl. Phys., 3(3), pp. 365-376.

[38] Noda, N., Hetnarski, R., and Tanigawa, Y., 2002, Thermal Stresses, Taylor \& Francis, London.

[39] Fickett, W., and Davis, W., 1979, Detonation, University of California Press, Berkeley, CA.

[40] de Malherbe, M., Wing, R., Laderman, A., and Oppenheim, A., 1966, "Response of a Cylindrical Shell to Internal Blast Loading," J. Mech. Eng. Sci., 8(1), pp. 91-98.

[41] Blevins, R. D., 1979, Formulas for Natural Frequency and Mode Shape, van Nostrand Reinhold, New York.

[42] Auslender, F., and Combescure, A., 2000, "Spherical Elastic-Plastic Structures Under Internal Explosion. Approximate Analytical Solutions and Applications," Eng. Struct., 22, pp. 984-992.

[43] Biggs, J., 1964, Introduction to Structural Dynamics, McGraw-Hill, New York.

[44] Tang, S., 1965, "Dynamic Response of a Tube Under Moving Pressure," J. Eng. Mech. Div., Proc. ASCE, 91, pp. 97-122.

[45] Reismann, H., 1965, "Response of a Pre-Stressed Cylindrical Shell to Moving Pressure Load," Eighth Midwest Mechanics Conference, S. Ostrach and R. Scanlon, eds., Pergamon, New York, pp. 349-363.

[46] Simkins, T., 1987, "Resonance of Flexural Waves in Gun Tubes," US Army Armament Research, Development and Engineering Center Technical Report No. ARCCB-TR-87008.

[47] Simkins, T., Pflegl, G., and Stilson, E., 1993, "Dynamic Strains in a 60mm Gun Tube-An Experimental-Study," J. Sound Vib., 168(3), pp. 549-557.

[48] Simkins, T., 1994, "Amplification of Flexural Waves in Gun Tubes," J. Sound Vib., 172(2), pp. 145-154.

[49] Mirzaei, A., Mazaheri, K., and Biglari, H., 2005, "Analytical Modeling of the Elastic Structural Response of Tubes to Internal Detonation Loading," Int. J. Pressure Vessels Piping, 82(12), pp. 883-895.

[50] Brossard, J., and Renard, J., 1979, "Mechanical Effects of Gaseous Detonations on a Flexible Confinement," Prog. Astronaut. Aeronaut., 75, pp. 108121.

[51] Van de Ven, A., Olivier, H., and Grönig, H., 1996, "Dynamic Structural Response of a Dust Detonation Tube," Seventh International Colloquium on Dust Explosions, Bergen, Norway, pp. 4.22-4.32.

[52] Sperber, A., Schildber, H., and Schlehlein, S., 1999, "Dynamic Load on a Pipe Caused by Acetylene Detonations-Experiments and Theoretical Approaches," Shock Vib., 6, pp. 29-43.

[53] Thomas, G., 2002, "The Response of Pipes and Supports Generated by Gaseous Detonations," ASME J. Pressure Vessel Technol., 124, pp. 66-73.

[54] Simkins, T., 1995, "The Influence of Transient Flexural Waves on Dynamic Strains in Cylinders," Trans. ASME, J. Appl. Mech., 62(1), pp. 262-265.

[55] Akbar, R., 1997, "Mach Reflection of Gaseous Detonations," Ph.D. thesis, Rensselaer Polytechnic Institute, Troy, NY.

[56] Chao, T., and Shepherd, J., 2005, "Detonation Loading of Tubes in the Modified Shear Wave Regime," Proceedings of the 24th International Symposium on Shock Waves, Z. Jiang, ed., Springer, New York, Vol. 2, pp. 865-870.

[57] Chao, T. W., 2004, "Gaseous Detonation-Driven Fracture of Tubes," Ph.D. thesis, California Institute of Technology, Pasadena, CA.

[58] Shepherd, J. E., Karnesky, J., Pintgen, F., and Krok, J. C., 2008, "Experimental Measurements of Strains and Blast Waves Resulting From Detonations in Tubes," Graduate Aeronautical Laboratories, California Institute of Technology, Technical Report No. FM2006.010.

[59] Deiterding, R., Cirak, F., Mauch, S., and Meiron, D., 2007, "A Virtual Test Facility for Simulating Detonation-Induced Fracture of Thin Flexible Shells," Int. J. Multiscale Comp. Eng., 5(1), pp. 47-63.
[60] Cirak, F., Deiterding, R., and Mauch, S. P., 2007, "Large-Scale Fluid-Structure Interaction Simulation of Viscoplastic and Fracturing Thin Shells Subjected to Shocks and Detonations," Comput. Struct., 85(11-14), pp. 1049-1065.

[61] Liang, Z., Karnesky, J., and Shepherd, J., 2008, "Detonations in $\mathrm{C}_{2} \mathrm{H}_{4}-\mathrm{O}_{2}$. Experimental Measurements and Validation of Numerical Simulations for Incident and Reflected Waves," Graduate Aeronautical Laboratory, California Institute of Technology, Technical Report No. FM2006-009.

[62] Shepherd, J. E., Teodorcyzk, A., Knystautas, R., and Lee, J. H., 1991, "Shock Waves Produced by Reflected Detonations," Prog. Astronaut. Aeronaut., 134, pp. 244-264.

[63] Liang, Z., Karnesky, J., and Shepherd, J., 2006, "Structural Response to Reflected Detonations and Deflagration-to-Detonation Transition in $\mathrm{H}_{2}-\mathrm{N}_{2} \mathrm{O}$ Mixtures," Graduate Aeronautical Laboratory, California Institute of Technology, Technical Report No. FM2006-003.

[64] Shepherd, J., Schultz, E., and Akbar, R., 2000, "Detonation Diffraction," Proceedings of the 22nd International Symposium on Shock Waves, G. Ball, R. Hillier, and G. Roberts, eds., Vol. 1, pp. 41-48.

[65] Thomas, G. O., and Williams, R. L., 2002, "Detonation Interactions With Wedges and Bends," Shock Waves, 11, pp. 481-491.

[66] Liang, Z., Curran, T., and Shepherd, J. E., 2008, "Structural Response of Piping Components to Detonation Loading," Graduate Aeronautical Laboratories, California Institute of Technology, Technical Report No. FM2006.008.

[67] Liang, Z., Curran, T., and Shepherd, J. E., 2008, "Structural Response to Detonation Loading in a 90-deg Bend," Proceedings of the 26th International Symposium on Shock Waves, Göttingen, Germany, Jul. 15-20, 2007, K. Hannemann and F. Seiler, eds., Springer, New York.

[68] Naitoh, M., Kasahara, F., Kubota, R., and Ohshima, I., 2003, "Analysis of Pipe Rupture of Steam Condensation Line at Hamoaka-1, (II) Hydrogen Combustion and Generation,” J. Nucl. Sci. Technol., 40(12), pp. 1041-1051.

[69] Chao, T.-W., and Shepherd, J. E., 2005, "Fracture Response of Externally Flawed Aluminum Cylindrical Shells Under Internal Gaseous Detonation Loading," Int. J. Fract., 134(1), pp. 59-90.

[70] Chao, T. W., and Shepherd, J. E., 2004, "Comparison of Fracture Response of Preflawed Tubes Under Internal Static and Detonation Loading," ASME J. Pressure Vessel Technol., 126(3), pp. 345-353.

[71] Lam, A., and Zielonka, M., 2002, "Fracture Response of Externally Flawed Thin-Walled Plastic Tubes to Gaseous Detonation Loading," Graduate Aeronautical Laboratories, California Institute of Technology, Report No. Ae104c.

[72] Brossard, J., and Charpentier de Coysevox, N., 1976, "Effects d'un confinement souple sur la détonation des mélanges gazeux," Acta Astronaut., 3, pp. 971-981.

[73] White, D. A., 1957, "On the Existence of Higher Than Normal Detonation Pressures," J. Fluid Mech., 2, pp. 513-514.

[74] Craven, A. D., and Grieg, T. R., 1968, "The Development of Detonation OverPressures in Pipelines," Inst. Chem. Eng. Symp. Ser., 25, pp. 41-50.

[75] Shepherd, J., 1992, "Pressure Loads and Structural Response of the BNL High-Temperature Detonation Tube," Brookhaven National Laboratory Technical Report No. A-3991.

[76] Boyack, K., Tieszen, S., and Stamps, D., 1993, "Internal-Pressure Loads Due to Gaseous Detonations," Proc. R. Soc. London, Ser. A, 443(1918), pp. 343 366.

[77] Kogarko, S. M., 1958, "Invetigation of Pressure at the End of a Tube in Connection With Rapid Nonstationary Combustion," Sov. Phys. Tech. Phys., 3(9), pp. 1875-1879.

[78] Chan, C. K., and Dewitt, W. A., 1996, "DDT in End Gases," 27th Symposium (International) on Combustion, The Combustion Institute, Pittsburgh, PA, Vol. 2, p. 2679.

[79] Zhang, F., Thibault, P. A., and Murray, S. B., 1998, "Transition From Deflagration to Detonation in Multi-Phase Slug," Combust. Flame, 114, pp. 13-24.

[80] Duffey, T., and Mitchell, D., 1973, "Containment of Explosions in Cylindrical Shells," Int. J. Mech. Sci., 15, pp. 237-249.

[81] Benham, R. A., and Duffey, T., 1974, "Experimental-Theoretical Correlation on the Containment of Explosions in Cylindrical Vessels," Int. J. Mech. Sci., 16, pp. 549-558.

[82] Hodge, P. G., 1956, "The Influence of Blast Characteristics on Final Deformation of Circular Cylindrical Shells," ASME J. Appl. Mech., 284, pp. 617-624.

[83] Duffey, T., 1971, "Approximate Solutions of an Impulsively Loaded Long Cylinder Governed by an Elastic-Plastic Material Law," Acta Mech., 11, pp. 45-57.

[84] Duffey, T., and Krieg, R., 1969, "Effects of Strain Hardening and Strain Rate Sensitivity on the Transient Response of Elastic-Plastic Rings and Cylinders," Int. J. Mech. Sci., 11, pp. 825-844.

[85] Fanous, F., and Greiman, L., 1988, "Simplified Analysis for Impulsively Loaded Shells,” J. Struct. Eng., 114, pp. 885-899.

[86] Young, W., and Budynas, R., 2002, Roark's Formulas for Stress and Strain, 7th ed., McGraw-Hill, New York.

[87] Pintgen, F., and Shepherd, J. E., 2007, "Elastic and Plastic Structural Response of Tubes to Deflagration-to-Detonation Transition," Explosion Dynamics Laboratory, California Institute of Technology, Technical Report No. FM2006005 .

[88] Koslowksi, M., and Lew, A., 1999, "Plastic Response of Thin Tubes to Gaseous Detonation Waves," Graduate Aeronautical Laboratories, California Institute of Technology, Report No. Ae104c. 